This is a self-archived version of an original article. This version may differ from the original in pagination and typographic details.

Author(s): Rodi-Risberg, Marinella

Title: Trauma and storytelling in Betty Louise Bell's Faces in the Moon

Year: 2018

Version: Accepted version (Final draft)

Copyright: (c) 2018 Taylor \& Francis

Rights: In Copyright

Rights url: http://rightsstatements.org/page//nC/1.0/?language=en

Please cite the original version:

Rodi-Risberg, M. (2018). Trauma and storytelling in Betty Louise Bell's Faces in the Moon.

Critique: Studies in Contemporary Fiction, 59(5), 562-577.

https://doi.org/10.1080/00111619.2018.1432557 
Abstract: The dominant understanding of trauma as an epistemological crisis that can be mimetically passed on to readers has been criticized in the twenty-first century for its apolitical and ahistorical orientations. As a way to assess this criticism, this article examines trauma and storytelling in Betty Louise Bell's Faces in the Moon (1994), a novel which places the trauma of sexual violence in a broader context of settler colonialism, examines trauma and storytelling in Bell's text as a way to assess this criticism. Reading the novel in dialog with American Indian studies and research on the writings of women of color offers an exploration of key aspects of trauma theory, such as the notions of unrepresentability, punctuality, transmissibility, belatedness, and passive witnessing. Ultimately, the novel not only anticipates today's increased mainstream recognition of gender violence against indigenous women, but serves as a potential harbinger of future political action through politically engaged reading.

\section{Trauma and Storytelling in Betty Louise Bell's Faces in the Moon}

\section{Marinella Rodi-Risberg}

Sexual violence experienced by Native American women has recently gained increased mainstream recognition and, in turn, raises issues of trauma, human rights, affect, and selfdetermination. The most frequently cited numbers are presumably that 34.1 percent, or more than one out of three Native women will be raped in their lifetime, according to a report from 2000 by the US Department of Justice (Tjaden and Thoennes 22). Statistics by the Centers for Disease Control and Prevention indicate that 49 percent of Native women report past sexual violence (Black et al. 20). ${ }^{1}$ According to the US Department of Justice, perpetrators are nonNative men in no less than 86 per cent of reported cases of rape or sexual assault against Native American and Alaska Native women (Amnesty International 4). This means that the majority of sexual assaults and rapes against Indigenous women are inter-racial, while victimizations committed against other women tend to be intra-racial (see Bachman et al. 
38). ${ }^{2}$ Moreover, this violence against Native women is greatly underreported (Amnesty International 4), so the story is only partially told. Even if reported, non-Native men evade tribal criminal sanctions if the rape took place on tribal lands (Deer 7). Present feminist Native scholarly discourses link this gendered sexual violence to a heritage of past human rights violation: Dian Million (Tanana Athabascan) called gender violence " $[\mathrm{t}]$ he abject heart of colonialism and neocolonialism" (Therapeutic 177), and Muscogee (Creek) Nation scholar Sarah Deer, sees rape as "a political issue with settler colonial foundations" (xxiv). ${ }^{3}$

Awareness of this connection between past and present traumas can help to make the need for social justice visible and the critique of this violence more effective.

The above references to social and historico-cultural events help position the present analysis of trauma in Betty Louise Bell's (Cherokee) Faces in the Moon (1994), which, like the numbers cited above, challenges American exceptionalism and the US as a safe haven that protects human rights rather than violates them. Whereas Ojibwe author Louise Erdrich's novel The Round House (2012) was motivated by the "one in three" statistic, Faces in the Moon instead emerges as prophetic to today's increased mainstream acknowledgment of gender violence on and off reservations. Bell does this by drawing attention to the connection between past and present traumas and their effects by mixing genres such as the novel form and Native storytelling and including different temporalities: ancestral ghosts, stories, and emotions from the past irrupt in the linear narrative present. Critics have read it as a feminist Bildungsroman with elements of magical realism, or a Kustlerroman that parallels ideological work performed by postcolonial literature, and observed its juxtaposition of linear and cyclical time. ${ }^{4}$ They fail, however, to realize that its generic and temporal innovativeness has to do with trauma in relation to indigenous cultural traditions. The text is a reaction to the consequences of sexual violence, poverty, and colonization experienced by Native peoples, and as such qualifies as a trauma narrative: ${ }^{5}$ it also displays the "generic hybridity" that 
characterizes trauma narratives (Andermahr and Pellicer-Ortín 8); the incorporation of a nonlinear narrative, presenting trauma in relation to ghosts through the notion of intergenerational transmission of trauma, also links it to paradigmatic trauma texts such as Toni Morrison's Beloved. ${ }^{6}$ Yet, it would be a mistake to see its non-linear aspects simply as a sign of trauma and not as intrinsic to oral traditions, and to view ancestor spirits as aspects of magic rather than grounded in Native beliefs and cultural traditions. ${ }^{7}$ The non-linear spiritual temporality and its link to storytelling in the novel disrupt the linear logic of progress on which colonialist stories depend and which erase Native presences and traditions. Additionally, it engages readers, who can experience through imagination the felt experience of trauma and oppression that the novel depicts, spurring them to politically engaged reading to possibly effect material change.

In analyzing Bell's novel, this essay uses the concept of trauma even though hegemonic Western trauma theories that pathologize social suffering jar disconcertingly with the collective and social characteristics of Native groups' experience of trauma, which is the result of power relations with the state. One of the most influential trauma theorists, Cathy Caruth, has offered a deconstructive understanding of trauma as an unspeakable, unknowable, and event-based experience that can be accessed only indirectly and belatedly as well as passed on to others as an experience that "is never simply one's own," and, thus, can "provide the very link between cultures" (Caruth, Unclaimed, 24; "Trauma" 11). Despite contemporary trauma theory's laudable intent at its inception in the 1990s to record the consequences of sexual, gendered, and racialized trauma in US history, in the twenty-first century it has been charged with Eurocentrism as well as a universalizing and depoliticizing approach in the face of colonial trauma (see, e.g., Craps 46; Craps and Buelens 2-3). As indigeneity is being reconceived from a universalizing identity to one which requires a historical awareness and consideration of particular places, the development of trauma theory 
has not proved a suitable vehicle for understanding the literature and history of Native Americans. Yet, because of their political identity as Natives, Indigenous peoples are situated in relation to the dominant model for "telling" trauma set by the Jewish Holocaust and World War II, precluding Native epistemologies and storytelling (Million "Felt", 64; Therapeutic 76-7). ${ }^{8}$ While contemporary scholarship sometimes situates Native American literature with postcolonial literature because of its themes of trauma, displacement, and sovereignty, ${ }^{9}$ Bell's novel illuminates the distinctive reverberations of US history in present sexual violence against Native women by exploring this present trauma as continuous with rather than post historical trauma. This highlights that the novel is conceived in a situation of ongoing colonialism: for the protagonists in Bell's novel, the present is intimately connected with the past through remembering, Native storytelling, and dreaming. This article uses the novel's form and themes as an intervention into theory, placing trauma theory in productive dialog with American Indian studies and research on the writings of women of color.

Exploring Native storytelling in a context of trauma in Faces in the Moon provides a way to assess criticism of hegemonic trauma theory for its apolitical and ahistorical orientations. Far from disregarding historical context and politics, Bell's novel resists apolitical and ahistorical readings by highlighting sexual violence in a broader system of oppression - forging a link between sexual trauma and the trauma of racism, economic disenfranchisement, and a settler colonial context. In this way, Bell's text actively provides a stinging critique of the violence, genocide, and rape that the US for more than 500 years has engaged in, and calls upon the reader to learn to see the interconnection between US aggressive history and present hurts. In this, Bell's text aligns itself with those of other women writers of color who, as Channette Romero has found, since the 1980s have attempted to recover the "political relations" between texts and readers of the early novel: through blending the traditional novel form with spiritual practices and oral storytelling associated 
with active audience involvement, they unsettle the "private, isolated experience" of reading novels, and so create "new politically engaged reading strategies" (25). Bell's novel emphasizes the emotional effects of the past; her telling can affect readers on an emotional level and spur them to actively engage with social issues. This sense of felt experience challenges the Western ideal of objective interpretation that suppresses and marginalizes Native history, traditions, and literature in US scholarly discourse, and may disrupt dominant understandings of trauma and open up for new ones.

Investigating trauma and storytelling in Bell's novel also offers an examination of some of the most debated aspects of trauma theory, including the notions of unrepresentability, punctuality, transmissibility, belatedness, and passive witnessing, and also suggests a form of literary activism. If trauma denotes temporal dislocation or displacement in terms of belatedness, in other words, if it shatters perceptions of time and place does it not potentially decontextualize traumatic histories and events? If trauma is seen as a pathologically dissociative rupture does it not tell us that traumatized individuals and groups, not society, need to change? If trauma is conceived of as a single event that is not experienced upon occurrence and demolishes referential access, how can it be testified to, passed on to others, and shared? And to identify with and partake of another's trauma, must the phenomenon not be seen to address specific contexts instead of being seen to exist in a form of an omnipast in the sense that the past is everywhere in traumatic symptoms? Bell's novel examines these controversial issues. The first part of the analysis investigates Bell's employment of storytelling as challenging the dominant understanding of trauma as an aporia of representation. Rather than emphasizing unnarratability, the novel offers a motivation to verbalization of trauma. The second part explores the link between past and present traumas in the novel. Bell breaks the silence and sheds light on the personal trauma of domestic sexual violence from a Native American perspective, linking it to the trauma of settler 
colonialism by addressing its repercussions in the form of today's gendered violence. This connection, in turn, upsets the notion of belatedness and the understanding of trauma as a single violent or original event in an individual's past, as well as complicates the idea of transmissibility. The novel also emphasizes the reader's responsibility to see the nexus between past and present suffering although the protagonists may not initially do so. The last part of the analysis focuses on the reader's role in the novel's literary activism, not only as a witness, but as a co-creator in Bell's attempt to (re)write/(re)right, through storytelling, colonialist discourses that silence women's stories of gendered violence, thereby questioning the notion of silence and passive reading as the only ethical response to trauma. ${ }^{10}$

\section{The Story of Trauma}

Faces in the Moon unites the political power of storytelling with realism to communicate the intricacies of a trauma narrative of sexual abuse in a context of settler colonialism. Set in Oklahoma, the novel tells the story of the mixed-blood Cherokee protagonist Lucie Evers's emotional journey from a sexually abused child, who lives trauma in poverty, to a woman who learns to act from a growing political and historical awareness. The novel is divided into six sections, and begins and ends with the voices of women telling stories and so is framed by them. The stories constitute the novel's center, its essential part. In this way, Bell braids a story evocative of an oral tale, reminiscent of spoken language, and the text itself is about the art of storytelling as testimony and partly also its medium. Narrated from the point of view of Lucie, it examines the childhood trauma of sexual violence through analepses as the adult Lucie returns to Oklahoma from California, where she teaches classes at a university, after she receives a phone call about her mother who has been taken to the hospital after a stroke. Lucie's remembering and attempts to come to terms with the past occurs through a double narrative voice and the events are focalized through Lucie either as a child or as an adult. The 
text thus presents two different focalizing strains which reflect the narrator's growing understanding of events as she pieces together a story of the past through memories and her mother's letters and journal. Bell's emphasis on storytelling and the spoken in the novel in the form of dialogs, letters, and Lucie's narrative re-creates an oral cultural and literary technique. In contemporary Native American literature, narrative technique is more hinting than explicit which underscores a listening between the words of a story and how it is told, to what is not directly shared in words (Blaeser 64). Lucie succinctly references this in Bell's novel, "I listened, their stories settling forever in my blood, and I knew the stories were told and told not for carrying but for keeping. They heard, and they taught me to hear, the truth in things not said. They listened, and they taught me to listen, in the space between words" (Bell 56-57). ${ }^{11}$ Initially portraying Lucie's mother as insufficient as when Lucie's white stepfather rapes Lucie at four, Lucie recovers the past through her mother's eyes and comes to understand the legacy of violence and also female strength and resistance. In this way, the novel challenges the kind of domestic and cultural imperialism that pathologizes and denigrates Native peoples and their capacities construing them as mere victims.

The novel's telling the story of trauma through mainly realist means unsettles one of the most often theorized features of traumatic experience as unspeakable or representable only in a certain way. For Caruthian trauma theory, trauma involves a certain paradox: trauma as an "unclaimed experience" produces an epistemological and ontological crisis that bypasses linguistic reference and is therefore knowable only belatedly in the form of repetitive and intrusive traumatic effects which are seen to literally represent the traumatic event (see Caruth Unclaimed). In other words, testimony is seen to presuppose unrepresentability. Thus, literature becomes an exclusive site for bearing witness to trauma through experimental postmodernist forms that reflect and pass on rather than represent the impact of the phenomenon to readers in its literality. These prescriptive formal sine qua non 
requirements for representing trauma and its reverberations, however, have been criticized for depoliticizing social suffering, for producing, as Alan Gibbs puts it, "emotional affect rather than political action" (20). Bell's novel conveys an affecting portrayal of trauma primarily through realist means, and in this her story not only fails to conform to the paradigmatic aesthetics of unspeakability, but also challenges essentialist analyses of Native American culture and literature. In fact, Bell's chiefly realist depiction of trauma may be more effective in affecting readers than postmodern aesthetics which, after having been repeatedly employed, may no longer be able to shock readers. For Gibbs, texts displaying a postmodernist aesthetics or what has become "conventional methods of representing trauma" in what he labels "the trauma genre" (34), have mainly lost their ability to affect readers; new realist forms may be more effective in this endeavor (36). It is not uncommon that ethnic fiction like Bell's novel employs realist devices for storytelling. Leslie Bow notes that "the marketplace for ethnic literature was initially governed by a desire for ethnographic reportage, making autobiography a standard genre in the field" (168-69). Realist texts with an activist agenda complicate analysis, however: "Because realism has the appearance of being documentary, its methods of persuasion can often remain invisible as the details and drama of events drive the narrative forward" (169). Thus, in realist fiction with an activist intention, appeals for justice, says Bow, "can subordinate rhetoric" (169). This is in stark contrast to texts of the trauma genre where form often takes precedence over content. In Bell's novel, the narrative strategy of storytelling produces meaning and significance.

Conceived from an experiential context, the novel offers a starkly realistic depiction of the traumatic lives of Cherokee and mixed-blood women, and draws on the imaginative power of Native storytelling to tell the trauma of gendered sexual abuse, underscoring felt knowledge. ${ }^{12}$ Informed by her own family history, Bell's Faces in the Moon calls attention to the gendered sexual violence confronting many Native and mixed-blood women today. Her 
mix of fiction and autobiography reinforces a sense of felt experience and achieves reliability. Although the publisher, University of Oklahoma Press, categorizes Bell's text as a novel, it also emphasizes documented historical proof as well as affect, saying on the back cover that "From this piece of her own family history, Bell has fashioned a first novel of impressive emotional power." Bell has written her story based on historical people and documented historical events, and thus conveys a sense of commitment to the past. She relates in her essay "Burying Paper" how Faces in the Moon has its origins in "the Oklahoma voices of my mother and great aunt" (35). She also recounts how she came comes to understand the legacy of abuse and gendered violence by reading her mother's journal: "these stories were different from the ones I had heard since childhood: these were the stories she could not tell a child, the stories of her life after her mother died, the stories of a nine-year-old mixed-blood girl taken into the bed of her white stepfather to negotiate shelter and food for herself and her two younger sisters" (36).

In its testimony to the emotive reality of trauma, Bell's novel re-produces her mother's experience of sexual abuse in novelized form, and explores the potential for resistance and coming to terms with a traumatic past through storytelling as an instrument for engaging an activist response from readers. ${ }^{13}$ In using storytelling as a tool for literary activism, she joins other contemporary writers of color who, as Romero has found, incorporate oral storytelling in their work for the purpose of engaging readers "in helping to construct the story to encourage active social engagement" (33). Bell shows readers how trauma and oppression work, giving readers a felt experience that may spur them to action. In other words, the politics is in the storytelling. Storytelling or story writing fiction such as Bell's stresses the role of an active audience. As Kimberly Blaeser (Chippewa) notes, "Native literatures have supra-literary intentions," and "[t]hey want to come off the page and affect life" (65): "Through speaking, hearing, and retelling, we affirm our relationship with our 
nations, our tribal communities, our family networks," and "[t]his communal identification comes about most fully when the oral involves an active exchange, when it incites response or a sense of response-ability in the listener" to "make the story together" $(54,54,64)$. Through storytelling reading becomes a dialogic activity in the sense that readers can envision their parts in the stories: these narratives implicate the reader as a response-abled witness. Whereas Lucie's mother's writing in her journal was merely a “craft, without a question of skill or training, never thinking of precedent or earning her art, trusting her story to win and hold her reader" (179), Bell has crafted her story to not only skillfully hold but also activate her readers. By using elements of dominant culture such as the novel form as a medium to represent Native oral storytelling tradition as efforts at resistance to enact change, she demonstrates that, as Simon Ortiz notes, "Indian people have creatively responded to forced colonization" through appropriating "foreign ritual, ideas, and material in their own Indian - terms" (254). Storytelling, which cancels the referential foundation in Caruthian trauma theory of trauma as unspeakable, allows readers to imagine a sharing of the suffering told and inspire an active relationship to readers, and so shows that emotional affect does not preclude political action.

In contrast to a postmodern aesthetic of aporia, Bell's novel is rooted in place, a specific cultural and historical context, which is in line with contemporary fiction by women of color (see Romero 67). Lucie relates through the novel her own story of trauma as connected to that of her family - her mother, her aunt Rozella, her grandmother Hellen, and her great-aunt Lizzie - and of her people. These were stories of "black-eyed Indian women raising children alone, chopping their way through cotton, good-ol' boys and no-good men. Full-bloodied grandmothers, mixedblood renegades and lost generations" (5). Thus, the novel challenges historical records that suppress voices of Indigenous women as well as reveals the origin of present traumas. Through stories, personal and cultural histories are 
interwoven with each other and with cultural legends. Bell uses italicized font throughout the novel to indicate deep emotion and perception, as in dreams, recall, important understandings, and for the voices of women and their impact on Lucie. Theirs are stories, Lucie relates, that "have grounded my sympathies, speaking through my spirit without time or place or will, Momma, Auney, Lizzie" (5-6). The power of Native storytelling not only derives from guidance but also from its spiritual connections (Romero 64). In Bells novel, departed ancestors are continuously present as faces in the moon, as voices talking, and in storytelling, which sometimes signals their presence, for instance, in the flapping of a curtain (19). This means that a non-linear narrative of storytelling disrupts the linear time of the plot. Additionally, what is anachronistic is not simply a postmodern aesthetics to reference trauma's alleged unrepresentability but part of the Native tradition of storytelling, which, in turn, interrupts the linear logic of progress of colonialist narratives that effaces Native presences and traditions.

The portrayal of Lucie's mother's seemingly incapacity to appreciate Lucie's pain reveals the cost of assimilation. Lizzie says that "the Cherokee always been a proud people. They took care of their children and families. That always come first. When my granddaddy come from Georgia he didn't leave no body behind. Nowadays seems like people forget how to look out for their families. But it ain't their fault, I reckon" (122-23). Studies corroborate Lizzie's words that in traditional Native families, physical and sexual violence against women and children were uncommon occurrences (Deer 21-22; Smith 130; Poupart 86; Hendrickson 13). Gracie has seemingly abandoned her origins in an effort at desperate assimilation to Western consumerism after a life of racial discrimination, cultural and economic imperialism and disenfranchisement. Yet, as Andrea Smith asserts, indigenous peoples "could never really assimilate into the dominant society" for the reason of racism; this means that the effect of the policy of assimilation "was to situate them at the bottom of 
the U.S. socioeconomic ladder" (37). As Lucie returns from California after the call about her mother's illness, she notes how her mother's hoarding of food in response to pain has become worse ${ }^{14}$ and is forced to face her childhood poverty and traumatic memories from which she has escaped by marrying (and subsequently divorcing) a rich man and moving to California. A challenge for readers is not to reinforce forms of cultural imperialism that pathologize indigenous peoples and undervalue their capacities and resilience by linking abuse to poverty, reproducing stereotypes that poor Indian families are dysfunctional. While, as Deer notes, sexual violence is "directly related to most of the social challenges tribal nations face, and when people are hurting, they cannot effectively govern themselves or provide guidance and support for the children in the community," "stereotypes of inferiority ... neglect to honor the resilience and survival of the people by focusing on the bad rather than the good" $(97,10)$. Although Bell communicates the psychological effects of internalized racism in the character of Gracie, Lucie (and the reader) finds out towards the end of the novel that Gracie is a strong struggling woman that loves her daughter. After finding "the beginning” of Gracie's story, recounted in her memoirs that Lucie finds when searching through her mother's house, Lucie, in an emotionally charged moment, finally understands and forgives her mother's negligence and inability to bond because it had been done to her, as it were. Gracie, too, grew up “abandoned and unprotected" $(175,184)$. Although it is not spelled out exactly what Gracie and Rozella's stepfather Jeeter did to them, if they were sexually abused or not, Gracie intimates that they were left with him when Hellen died and that he had used them "like he used his mules," adding "only worst" (159). Lucie burns the journal and tells her mother's story as well as her own throughout the novel; this significance originates in the structure of the text as a fictional recall.

Faces in the Moon repeats aspects of Native American (women's) narratives of gendered violence from the 1980s: the novel's shift from story to history, its story of female 
violation spanning several generations, and its narrative layering of stories within stories are features of such works as author Louise Erdrich's Love Medicine (1984); yet, in situating rape at the center of the novel and linking it to colonization, Bell vaticinates Deer's recent research about sexual violence against Indigenous women. Deer's monograph explains how the "legacy of rape must be explored and documented in order to reclaim authority and understanding about the contemporary context in which rape occurs" (112). Bell's novel elucidates this through including an almost six pages long segment of unadulterated history in the middle of the novel that chronicles how a member of Lucie's family strives to retain tribal lands, a history of which mainstream Americans may not be aware, and through focusing on the specific effects of Cherokee removal and allotment as a historical context for the contemporary abuse of Cherokee women. In other words, positioned in the referential frames of Native resistance to colonization, the protagonist Lucie, on the one hand, references the historical period of allotment and removal, representing the damaging consequences of colonization, the confiscation of tribal lands, and resulting displacement, that is, trauma experienced collectively by her people. On the other hand, she raises awareness of today's gendered physical and sexual violence against women and children which originates in socioeconomic marginalization and exploitation, racism, and the destruction of traditions as ongoing effects of colonization. To Cherokees, as Daniel Heath Justice's (Cherokee Nation) indicates, the notion of Removal is not just "a symbol of erasure, the exile of a community from homeland and hearth," but "a historical trauma that continues to reverberate in the memory and cultural expressions of Cherokees today" $(60,47)$.

Placing literary trauma studies in dialog with scholarship on Native women and women of color alters our conception of characterization. In Bell's novel, the protagonist partly becomes culturally representative not only of gendered violence in Indian country but also of the Cherokee experience of allotment and removal. This aligns the text with 
contemporary American trauma novels where, as Michelle Balaev noted, the protagonist, in addition to "express[ing] a unique personal traumatic experience" also becomes "a representative cultural figure" whose purpose is to "reference a historical period in which a group of people or a particular culture, race, or gender have collectively experienced trauma" in order to increase the knowledge of particular historical events $(17,16,17)$. As Vickroy indicated, writers of trauma "retranscribe a chronicle of facts into literary codes; they create allegorical narrative accounts of historical time periods" (37). The notion of a cultural figure in literary trauma scholarship resonates with Romero's findings in fiction by contemporary women of color writers; "characters are seen as products of their cultural communities, and these communities are often portrayed as three-dimensional characters in their own right," in this way, "characterization in these texts constitutes the shared traits of several individuals in a community" (34). Consequently, protagonists do not merely act as cultural figures but reveal to readers the consequences and effects of power systems on individuals and whole communities. In Faces in the Moon, the protagonists illuminate the emotional pain of Native Americans of the effects of The Allotment era of 1887-1907, which is when Indian Territory was divided by the General Allotment Act of 1887 and the state of Oklahoma was created in 1907, and removal as in the Removal Act of 1830, as a link to today's gender violence.

\section{Traumatic Stories: Sexual Violence and Settler Colonialism}

Through imbricating sexual violence, domestic abuse, and poverty with US settler colonialism, Bell's story calls attention to that not only individuals but whole communities suffer the consequences of trauma. Native Americans have undergone organized genocide in the form of unprovoked killings and violent attacks sanctioned by the government, rape, theft of land, forced removal and relocation, and economic dispossession (see, e.g., Poupart 87). The program of colonial aggression, Smith notes, "establishes the ideology that Native bodies 
are inherently violable - and by extension, that Native lands are also inherently violable": in fact, "U.S. colonizers view the subjugation of women of the Native nations as critical to the success of the economic, cultural, and political colonization" $(12,15)$. Faces in the Moon clarifies and conveys for readers the felt and ongoing effects of US interference in tribal government and law and foresees present US discussions about sexual violence against Native women as echoes of a history of sexual violence and genocide. In her important novel, Bell intertwines the telling of private and collective violence to elucidate that American intervention in tribal government and law not only subjects Native women to sexual assault at present, but also that this interference is firmly rooted in abusive colonial power.

Faces in the Moon relates a story of sexual abuse as already stained by colonization and the historical trauma of settler colonialism and this, in turn, upsets trauma theoretical notions of belatedness, transmission, and punctuality and blurs distinctions between individual and collective trauma. In other words, trauma is not conceived of as a single event that demolishes perceptions of time and referential access, and therefore repeatedly literally revisits the traumatized individual in intrusive images and compulsive behavior as reenactments of the trauma, but is seen as continuously affecting individuals and communities in the present. Colonial maneuvers of the past echo in today's sexual violence as a device "by which certain peoples become marked as inherently 'rapable"” (Smith 3), or in what is referred to as the "rapeability" factor" that originates in the US's longstanding history of sexist and racist anti-Native American policies (Deer 9). The methods used by colonizing institutions are largely the same as those used by perpetrators of sexual violence. These "tactics" include "deceit, manipulation, humiliation, and physical force" (xx). In addition, as Deer notes, owing to "the sense of possession and displacement," the psychological effects of sexual abuse and of colonization are similar, although "the impact of rape on an individual can be compounded by the influence of this historical trauma, and the 
survivor may experience a rape as part of a larger policy to silence, disempower and ultimately destroy her nation" $(113,112-113)$. Sexual violence against Native women assails both their identities as women and as Natives (Smith 8). As Bell's novel emphasizes, not only do Native people suffer due to historical events and actions that continue to inform their present lives, but the practices of colonization offer a model for today's gender violence against Native women in the US. Consequently, the methods that are used to traumatize individuals and collectives are transmitted, not the trauma per se.

In one of the most dramatic scene of the novel, these intertwined stories of individual and collective trauma result in a violent interracial rape of Lucie's four-year-old body by her mother Gracie's white boyfriend J.D. The rape exemplifies the sexual violence against women and children that Deer focuses on in her treatise. Bell questions individualized interpretations of sexual abuse by seeing these acts as part of a larger context of oppression. The rape scene draws attention to the incommensurate number of Indigenous women who are subjected to sexual violence. In addition, Bell links this gendered violence to social factors including racial discrimination and exploitation of Native Americans as a group, factors which are seen in the novel as consequences of settler colonialism and forced assimilation practices. Bell contextualizes this as a culturally emblematic event collective of women victims of rape. Here a private form of trauma, sexual abuse, references a historical experience of colonization to show its enduring consequences.

The rape incidence begins the novel's fourth segment, "Traveling Back," and depicts the adult Lucie's recollection of the novel's core event, focalized through a four-year-old Lucie. This scene forcefully demonstrates how Lucie becomes a cultural figure who represents the painful legacy of colonization, forced assimilation, and racial discrimination in the form of prevalent sexual abuse here perpetrated by J.D. J.D is a drunkard supply sergeant at Fort Sill who steals food, alcohol, and cigarettes from the government, and who also 
physically abuses Lucie and her mother: the abuse comes to embody historical rape in a way that interrelates personal to public, individual rape to historical rape. Christina Roberts has perceptively noted the significance of Bell's strategic placement of J.D. at Fort Sill, an army installation built during the Indian Wars in 1868, which is also later transformed into the reservation for the Kiowas and Comanches $(105, \mathrm{n} .3)$. This drives home even more that J.D.s rape of Lucie symbolizes elements of historical violence and resistance. The rape scene echoes the one of Bell's mother's experience of sexual abuse described in "Burying Paper" and follows immediately after J.D. has verbally abused Lucie delivering an ethnic slur calling her "Injun trash" which brings home to readers what Smith says about gender violence being "not simply a tool of patriarchal control, but also ... a tool of racism and colonialism" (1). As a powerful link between today's gendered violence and colonization the scene of the rape deserves to be quoted in full:

Lucie looked at him, stared at his pitted face.

"Scum," she said.

Her hands flew to her mouth. The sounds of apology were beginning when the fist struck her face. She covered her face as he dragged her across the linoleum by her hair.

“I'm gonna teach ya a lesson you ain’t gonna forget. Now'n you shut up or I'm a-gonna make it hard on ya." She tried to swallow her sobs, but they refused to stay down. She saw Momma, sleeping. He tightened his hand around her face and locked her mouth. With his other hand he unbuttoned her nightgown and fished it down her shoulders. Her body lay lifeless beneath him as he pulled her cotton panties down.

"There was the flash of pain and the taste of vomit. In the same dizzying flash the pain took the fear. I know now that fear left me that 
morning. I began to plan to kill him. I kept my eyes down, I didn't look at him, but I watched for my chance." (68)

In Lucie's remembering this incident, Bell replaces the third-person neutral reporting of fact in the first part of Lucie's recall with an italicized first-person focalization that illuminates Lucie's intense emotions. This aligns her also with other trauma writers who, Vickroy indicated, "can create a felt sense of life in their visceral portrayals of the intimate ways trauma is experienced in the body" (25). The sudden narrative shift between third and first narrator voice demonstrates the change of the protagonist's feelings as she recalls her experience and marks Bell's desire to communicate significant deep emotional wound(ing) of the individual as well as the collective trauma of the past.

In the rape scene, two seemingly independent incidents and temporalities come together; the experience of present gendered violence against Native American women and the historical violence against Native people and tribal land expropriation by European settlers, forging a connection between current and historical oppressive contexts. J.D. represents a society that will silence Lucie and her story, "Now'n you shut up," but, as he warns, his actions will continue to have a prolonged or continuing effect in her life, "I'm gonna teach ya a lesson you ain't gonna forget." The protagonist's gendered and racialized body emerges as a territory being invaded, conquered, and colonized, and becomes a site where the familial trauma and its links to her Native American identity are played out. Thus, the violated female body is represented as a witness to not only a past and private childhood sexual trauma but also a history of violence with which the private trauma is connected. In this, it typifies Deer's description of rape "as an individualized manifestation of colonization" (134).

Faces in the Moon does not equate sexual violence at home with colonialism but shows that the perpetrator performs in a role that is informed by colonialist discourses. Here 
the novel offers a view of trauma, not as a pathological return to a previous incident in the protagonist's life but a return to an event that happened generations ago to her ancestors, which complicates the notion of trauma's time as belated. In this, it is historically specific and follows a tribal epistemology where events from forbears' past may influence future generations and vice versa, challenging the notion of the universalizing transgenerational transmission in trauma theory. As Deer observes, all Native people share a historical experience of invasion, colonialism, and conquest by inimical outside forces which is similar to rape: "Rape victims experience the same dynamic, but it is played out on their bodies and souls rather than on the land" (xiv). The rape of Lucie by her white stepfather references the colonial process of Native Americans that Duran described as "a collective raping process of the psyche/soul of both the land and the people" (21). The protagonist's development in Bell's novel is positioned in relation to a historical context of Native opposition to colonization, land allotment, and removal, and, consequently, Faces in the Moon invokes the individual trauma of sexual violence as intertwined with the collective experiences by Native Americans of forced assimilation, racial discrimination, and socioeconomic marginalization.

Bell's text also demonstrates how the historical trauma of raping the earth not only impacts the people and the cultural world, but also the natural world and how this hurt is interconnected. The earth is also shown to be raped and genocided in the image of the red earth of Oklahoma and to react to the trauma that is happening to the people. Bell highlights the connection between the land and the people, stressing that the red earth of Oklahoma contains a long history of suffering and shedding of blood: Linking the red of the earth with blood is reminiscent of the Native notion of earth wounding. Says Duran, "when the earth is wounded, the people who are caretakers of the earth also are wounded at a very deep soul level" (16). After the rape of Lucie, J.D. makes Gracie choose between him and her daughter and the next morning Lucie is sent away to Lizzie, her grandmother's sister-in-law, and her 
husband, Uncle Jerry, for 2 years (until Lizzie dies). The conversation when on their way to Lizzie and Jerry links the bloody rape of Lucie with the bloodshed of the past historical trauma of settler colonialism and colonization. Lucie asks her mother: "Does the dirt bleed?" "Maybe there's people buried under that dirt?" (71). "Maybe," Gracie replies, "Lord knows enough people have died in this state" (71). Uncle Jerry's father says "this here earth lives for Indian blood. It's taken so much blood it can't git back to its natural color. He always said, this ain't no Indian Territory, it's a Indian cemetery" (148).

The novel focuses on a simultaneously difficult and affectionate relation with the land, because whereas the image of the red earth denotes pain and suffering, its red color is also a Cherokee symbol of power. The indigenous people are connected to the land through feelings (Romero 158), and for Lucie, a retribalization process begins after the rape when she stays with Aunt Lizzie and Uncle Jerry; she learns to become Cherokee in the sense of connecting to traditions, Indigenous knowledge, and the land as well as reconnecting with nature. The reconnection to the natural world resonates with Balaev's notion that the landscape in the world of American trauma novels "creates and defines notions of culture, identity, memory, and place, along with the contradictions of such imaginings" (xii). Balaev proposes that "the description of place in the [American] novel's representations of trauma situates the individual experience within a larger cultural context that shapes the memory and value of an event" (xv). Bell has a geographic relatedness to her novel that can be seen as originating in the red earth of Oklahoma. Lucie's Cherokee identity cannot be disentangled from her people's land in the sense of an essential connection between the self, land, and community. Trauma may cause a disruption in the sense that it interrupts this connection, and Bell's novel typifies such a lack of interrelatedness in its representation of the mixed-blood protagonist. Lucie subsequently reengages with the land and her identity is formed by the negotiations between Native traditions and the impact of the dominant society and trauma. 
As her brain attempts to process the rape trauma Lucie actively connects with place to heal. Dreaming is one way in which Lucie engages with the history of the land and her memory of the abuse. Lying back on the bank of the creek one day, where she used to catch fish with Uncle Jerry, Lucie dreams (for over three pages), which suggests that the surrounding landscape becomes a place where the emotional action of the plot is played out. She dreams about her grandmother Hellen, forging a connection also between generations and between the world of the living and the world of the dead. Through dreaming Lucie establishes a connection with her family history and with dreaming itself as an important part of traditional Native beliefs. Through dreaming, the novel suggests, it is possible for Lucie to enter into another dimension as real as the "real" world, and to blur the boundaries between the past and the present. The dream world also becomes the field of action where Lucie confronts her past, individual and collective. The dream is also about the legendary mixedblood Comanche chief Quanah Parker who influenced Native people in the Southwestern US, and whom Lizzie's mother had met: "a man like that ain't got just one time and place," Lizzie's mother had said, but "is liable to turn up anywhere he's called" (143-44). Lucie dreams that Parker had come home for her, as her father, and "reached down and pulled her onto his lap" (151). In the dream story, she also sees her stepfather, which indicates that she engages with the memory of the abuse. J.D. and his connection to Fort Sill, which became the place where Quanah Parker surrendered in 1875, also comes to represent colonial violence; in Lucie's dream, however, J.D. is lynched by the crowd and Parker remains the hero. The dream world is here depicted as a locus in which Lucie may imagine the circumstances in which she may create her own version of truth, even negotiating dominant Western stories of events. Dreaming in this context is also significant in that it reverses time and thus causality. ${ }^{15}$ By (re)writing/(re)righting the ending of her story in the dream, causality is reversed and the past has loosened its grip on her. The dream blurs the boundaries between 
individual and collective trauma as well as between the present time and the past, and so allows for the beginning of a new story.

\section{Reading and/as Active Witnessing: Beginning a New Story}

At the novel's end, Bell's representation of the link between individual and collective trauma complicates the role of the reader as witness. Trauma theorists have most often focused on the reader's role as empathically witnessing stories of trauma. Unarguably the most famous statement about the listener's part is Dori Laub's insistence that "the listener to trauma comes to be a participant and a co-owner of the traumatic event" (Felman and Laub 57). ${ }^{16}$ Reading Bell's novel in dialog with trauma theory the need to critically analyze trauma theory's ethical and political stance emerges: trauma theory largely failed in their laudable intent to record the effects of sexual, gendered, and racialized trauma in US history and has often neglected to empathize with and witness stories by those classified in the West as "other," including Indian people. As I indicate elsewhere, issues pertaining to "how, what kind of, and whose trauma is depicted by whom and for whom, ... which texts are identified as trauma texts and which are not, which experiences or events are identified as traumatic and which are not, ... who benefits and who do not from these understandings," ultimately have both

political and ethical ramifications (Rodi-Risberg forthcoming). ${ }^{17}$ The novel's emphasis on active witnessing challenges trauma theory's tenets of aporia and stasis as the only ethical and responsible response to trauma because an aporetic dictate may preclude political awareness and hence ignore or depoliticize social issues. ${ }^{18}$ In her contribution to Encyclopedia of North American Indians, Bell claims that "Native American fiction and poetry are a literature of protest - the theft of land, language, heritage - and such protests will always be their defining characteristic" (340), a statement that is certainly true of Faces in the Moon. 
Largely brushed aside by Americanist as well as literary trauma scholarship, the novel, like other contemporary US fiction by women of color, instructs readers about social and political concerns without necessarily providing solutions and instead inspiring and enabling readers to create political awareness and understanding for themselves (see Romero 32). ${ }^{19}$ Rather than offering utopian schemes in which all problems are remedied, contemporary fiction by women of color seek to demonstrate "how the beliefs of people of color can be used to inspire pragmatic, politically useful, and historically aware resistance movements" because it "focus[es] on the hard work and ongoing process of enacting social change" (Romero 176). Bell's novel highlights traumatic experiences and events that are eliminated from official records as these oppose the US self-image of a nation that protects human rights. The work of setting aright the official record, of writing back and correct mainstream versions of the past, also functions as a history lesson for readers because, as Justice points out, the forced location of Cherokees "is largely glossed over in U.S. history texts" (60). Faces in the Moon can be seen as paying homage to those Cherokees who suffered and gave their lives in a context of the forced resettlement of Native American people to Oklahoma. Bell's text fills in gaps and struggles against misrepresentations of her testimony by chronicling a wide time range of the American past, from late nineteenth century to the contemporary period, and illustrates the useful part played by literature in introducing historico-cultural discourses in which the protagonist's marginal voice provides an alternative historical understanding that assists Bell in her social critique.

Bell's novel challenges the more passive witnessing of traumatic events exemplified in trauma theory by attempting to activate readers, which resonates with fiction by contemporary women writers of color. Romero puts the point, "If the readers choose to empathize with the characters and situations portrayed, they become implicated in the story of social injustice and obligated to think about their connection to the society that tolerates 
such injustices" (42). In this way, readers learn to see things from another perspective and "are asked to choose between the dominant ideology that led to the injustice, or the more marginalized worldviews represented in [these] texts" (42). In her historical revisionism of telling the story of a marginalized people, Bell articulates the meaning of testimony and her book can be read as a call for awareness of the oppression and violence suffered by Cherokees, and for social and political change, seeking to shed light on part of what Duran called the "hidden transcripts of American history" (22). Her storytelling voices and aims to repossess her people's collective history, by giving a profound importance to the Indian Territory and examining the consequences of allotment and removal on Cherokees today. It represents historical recovery work in that Bell challenges and (re)writes/(re)rights stories that erase Native Peoples' past and present presence from historical memory into new stories that not only bear witness to the struggles of her forebears but also to Native Peoples' current lives.

The novel's last scene takes place years after Gracie's death as Lucie returns to Oklahoma City to file an amended death certificate for her grandmother Hellen. This instance evokes past hurts as her act also represents aspects of her people's historical battle as they struggled to reinsert their rights: her present struggles to file the amended death certificate for her grandmother represent aspects of Native historical efforts by Cherokees in the past to repossess their rights and tribal lands, and reveals the correspondence between individual and collective experiences of violation. This time the past is brought back to be rewritten, however. If the past can be rewritten, a different future can be envisioned. The white librarian jokingly asks her who she thinks she is before handing her the Cherokee Rolls:

I speak slowly, deliberately, beyond the rush of anger, blood talking low and clear. 
"I ain't asking you to tell me who I think I am. I am the greatgranddaughter of Robert Henry Evers, I am the granddaughter of Hellen Evers Jeeters, I am the daughter of Gracie Evers, the niece of Rozella Evers, and the grandniece of Lizzie Sixkiller Evers.”

"Let me put it to you this way. I am a follower of stories, a negotiator of histories, a wild dog of many lives. I am Quanah Parker swooping down from the hills into your bedroom in the middle of the night. And I am centuries of Indian women who lost their husbands, their children, their minds so you could sit there and grin your shit-eating grin."

"I am you worst nightmare: I am an Indian with a pen.” (191-92)

(Re)writing/(re)righting the archive is not only a means of healing for Lucie and her family, but also an act in which her felt experience of righteous indignation is expressed. In an emotionally powerful moment, tired of years of indignities, Lucie calls up the spirits of her family as well as Quanah Parker. Explaining her behavior with "it's nothing personal," "I've just had one too many white men in my life" (192), Lucie also refers to J.D., which links her private trauma to the trauma of settler colonialism. The anger she feels she has seen on her mother's, her aunt's, and her great-aunt's faces, even "across Uncle Jerry's simple face" (191). In this she rewrites the social construct of Native Americans "as incapable of experiencing emotional responses to pain and suffering" although "the intense historical unresolved grief and pain that exists is accompanied by an extreme rage at the dominant culture for abuses past and present" (Poupart 89). For the reader, it would be irreverent to the narrator to disregard this anger as misguided. Lucie's expressed anger and her actions are here validated by the voices of her forebears as she can hear their steps "above and below, 
small quick steps, moving with the force and lightness of ghosts" and their "clucking and giggling ... 'Don't mess with Indian women"” (193). These voices communicating with Lucie not only indicate support of Lucie's justified rage, but also demonstrate that her actions call to mind a shared feeling or wish to (re)write/(re)right the historical record. Thus, Lucie's present act symbolizes historical efforts to (re)write/(re)right colonial violence, to affirm Indian rights, and reclaim land they were first robbed of by the colonizers and then by their successors, and which led to poverty and abuse. The maxim references Bell's own family history: "Don’t mess with Indian women" comes from her mother who, as Bell explains in her essay "Burying Paper," concluded her stories with it, indicating that "she had ancient hidden powers" (35). Maxims, non-linearity, and lack of closure are characteristic of storytelling and encourages reader involvement (Romero 32).

Lucie begins a new story that has meaning in relation to the story of her family and her people; her suffering is not apart from but a part of her family past and the history of her tribe. Bell's story offers readers the emotional effects of social oppression and domination as played out through women's present traumas, offering readers an emotional context for historical understanding. With her novel, Bell centers women's voices thereby decentering dominant colonialist stories as an attempt to right US historical violence against her people. Focusing our attention at the sexual assaults perpetrated on Indigenous women forces us to face the part played by the state in committing gendered and racist violence (Smith 3). Interested in revealing Native groups' power relations with the state, Bell's novel suggests that violence against women and children constitutes a real and felt part of today's Native American experience and creatively shows how this private violence is linked to the aggressive past of the United States. By having the narrator face the incest in her past and becoming aware of how this experience is linked to her family's history and that of her 
community, Bell emphasizes the importance for authors and scholars of (re)writing/(re)righting the grand narratives of history written by the colonizers.

Critics have emphasized that the novel's last scene bespeaks empowerment through writing as an instrument of struggle. Although Arnold Krupat does not mention the sexual abuse in the novel, he underscores Lucie's fighting back "with her voice and her pen" underlining that she is "an Indian woman with a pen" $(87,86)$ : "There is imagined $\ldots$ the necessity of writing, of producing tradition and community, specifically the community of Indian women who today may draw their lives from each other not only at the kitchen table but in a wider world beyond" (86). Similarly, Christina Roberts suggests that "Lucie claims the pen as a weapon and tool that can be used to emend the historical record, an implement vitally necessary in her role as storyteller and one that has transformative power" (103). The two analyses are persuasive in that they stress the transformative power of writing. Yet, reading the novel in dialog with trauma theory and women of color scholarship emphasizes the reader's role as witness. The scene revokes the linear logic of progress and closure on which colonialist narratives rely and offers a way for readers to be active witnesses and imagine a different future.

Placing the novel and the theory it challenges in a historic context revives Bell's novel for today's readers_-positioning it as prophetic of present terrifying moments. In addition, it indicates something about how literary criticism and the writing of fiction can be seen as features of the zeitgeist or spirit of the time and context of their conception and reception and how these can serve as potential harbingers of forms of future political action.

\footnotetext{
${ }^{1}$ Through her work to end violence in Indian country, Sarah Deer underscores that she has repeatedly heard "I don't know any woman in my community who has not been raped" (5).
} 
${ }^{2}$ Native communities have the highest rate of per capita rape in the country, and $57 \%$ are white offenders (Bachman et al. 38).

${ }^{3}$ The clinical psychologist Eduardo Duran, too, suggests that the high incidence of sexual violence present in Indian Country must be understood in relation to the historical trauma of colonization (88).

${ }^{4}$ For Helen May Dennis, Faces in the Moon is "an autobiographical novel" that has a "Bildungsroman agenda in terms of its plot" (104). Whereas "Western time predominates throughout the novel," flashbacks are used to match the forward motion with recalls of the past, the protagonist's "need to remember her life and the life of previous generations of her family" $(104,112,117)$. Arnold Krupat reads Bell's novel in relation to postcolonial literature as "written in a sophisticated mode of realism (i,e., a realism after modernism)" (86). Similarly to Dennis, Krupat comments on its form as "contrapuntally play[ing] a circular structure of return (back to the old ones, to kitchen-table talk) against a linear structure of 'progress' (forward to self-discovery and writing)," and views it as a subgenre of the Bildungsroman, "a female kunstlerroman - a portrait of the artist as a young woman charting the narrator's progress as an outward ... movement into the world ... [that] depends on a centripetal structure of return, one that... takes place in memory or imagination" $(86,86$ 87).

${ }^{5}$ According to Laurie Vickroy, "trauma narratives have emerged over the past thirty years largely as personalized responses to late twentieth century's and early twenty-first century's coalescing awareness of the catastrophic effects on the individual psyche of wars, sexual and physical assaults, poverty, and colonization" (1).

${ }^{6}$ Bell's employment of ancestor spirits should not be seen simply as a recycling of what has become formulaic narrative strategies of trauma fiction, but as relevant to the text's specific thematic context of oppression and resilience in Native America. See Gibbs (76-77) on how 
the innovative narrative devices, including trauma as haunting in the trope of the ghost in Beloved, which were historicoculturally and ethnically specific to Morrison's novel in its representation of the traumatic effects of slavery on African-Americans, have become near ubiquitous in later trauma texts dealing with other traumas unrelated to that context, and seen as aspects of trauma itself.

${ }^{7}$ Channette Romero emphasizes that magical realism is a construct created by "Europeaneducated, secular Latino male writers" to unsettle European Enlightenment epistemologies; for this purpose they depicted the spiritual beliefs in Latino/a folk tales as mere superstition or as unrelated to local religious practices and beliefs (35-36).

${ }^{8}$ Irene Visser claimed that the dominant Western trauma model needs to enlarge its aesthetics in conjunction with postcolonial theory "to theorize not only melancholia and stasis but also processes inducing resilience": as it stands, it is unsuitable for analyzing Indigenous literatures that examine trauma in relation to spiritual beliefs, such as in the form of ceremony and ritual, because it "does not acknowledge spirituality as a reference point; indeed, its deconstructivist mode denies the possibility of regeneration through ritual and belief systems" (279). I would add that this hegemonic trauma model also needs to be brought together with Native American scholarship and women of color studies.

${ }^{9}$ See, for instance, Deborah Madsen's Beyond the Borders: American Literature and PostColonial Theory (2003) and Amritjit Singh and Peter Schmidt's edited volume Postcolonial Theory and the United States: Race, Ethnicity, and Literature (2000).

${ }^{10}$ The notion of (re)writing/(re)righting nods to Kimberly Robertson's (Muscogee Creek Nation) efforts to "rewrite/reright the position of Native women in antiviolence discussions by centering their voices and concerns and, accordingly, by decentering the mainstream, colonialist narrative that typically frames such narrations" (22), and to what Nancy Miller and Jason Tougaw refer to as "writing wrong" in a context of trauma, "an attempt to right wrongs, 
to refuse to keep private, solitary suffering locked away, to put one's story into the public domain" (14).

${ }^{11}$ Hereafter the page numbers will refer to Faces in the Moon unless otherwise indicated.

${ }^{12}$ In this, Bell anticipates Million's concept of "felt theory" that recognizes visceral knowledge derived from experience, memory, and physical senses, thus legitimizing women's lived, actual experiences as worthy sources of knowledge. Highlighting the historical origins of affect and trauma in an Indigenous frame, Million claims that the US has "resisted the truth in the emotional content of this felt knowledge: colonialism as it is felt by those whose experience it is" ("Felt" 58).

${ }^{13}$ Storytelling is also a tool for recovery after sexual violence. Deer stresses that "The most important sources for the process of recuperation are oral traditions, stories, and traditional belief systems, as well as statutes and contemporary tribal appellate case law that sometimes encompass the traditional belief system" (xv).

${ }^{14}$ Duran saw addictive consumerism as an expression of internalized oppression, which "is expressed .... as either an ignorance of culture or an aspiration to identify with mostly White middle-class consumer values" (81).

${ }^{15}$ As Madsen points out in another situation; "Reverse causality is important in the context of trauma theory because ... Caruth's theory of trauma's 'belated temporality,' presumes a linear relationship between past and present that permits the possibility of entrapment in a traumatic past" (67).

${ }^{16}$ The historian Dominick LaCapra has issued a word of caution regarding this position in trauma theory, saying that readers/listeners must carefully navigate between sympathy and distance to avoid over-identification, secondary traumatism, and appropriating the trauma of another. Additionally, he feels that trauma theory must be careful that psychoanalytic concepts are not used as an excuse for refraining from engaging with social and political 
concerns (ix). For this purpose he favors a mode of "empathic unsettlement" in which readers retain a certain critical distance to texts that communicate traumatic experiences (78). From a literary perspective, Elizabeth Outka emphasizes that even if an author "transmits an experience" to readers it "does not mean the readers themselves are traumatized in a similar way," because "readers have not experienced the precipitating trauma, they may experience the symptoms, but the originating traumatic moment is not lurking within their consciousness" (32).

${ }^{17}$ As the pain of those that are classified as "other" in Western conceptions of Otherness are often neglected by trauma theory, it makes it, as Susannah Radstone argued, "a theory that supports politicized constructions of those with whom identifications via traumatic sufferings can be forged and those from whom such identifications are withheld" (25). On Native Americans as Other, see Lisa M. Poupart (Ojibwe), who remarks that Western society has "enforced its cultural codes of Otherness upon American Indians to gain our complicity in the power structure" for more than five centuries "of social, political, and economic domination" (87).

${ }^{18}$ Visser reflected that trauma theory prevents political awareness because "the concept of the cathartic role of literature as testimony overlooks political concerns" (278).

${ }^{19}$ I gratefully acknowledge the anonymous reviewer's suggestion that one reason for Faces in the Moon being relatively little known may be because Bell has not generated an extensive body of fiction; it is to date Bell's only novel. 


\section{Works Cited}

Amnesty International. Maze of Injustice: The Failure to Protect Indigenous Women from Sexual Violence in the USA. New York: Amnesty International USA, 2007. Andermahr, Sonya, and Silvia Pellicer-Ortín. "Introduction." Trauma Narratives and Herstory, edited by Sonya Andermahr and Silvia Pellicer-Ortín. London: Palgrave McMillan, 2013, pp. 1-10.

Bachman, Ronet et al. "Violence against American Indian and Alaska Native Women and the Criminal Justice Response: What is Known." 2008. https://www.ncjrs.gov/pdffiles1/nij/grants/223691.pdf. Accessed 3 May 2017.

Balaev, Michelle. The Nature of Trauma in American Novels. Evanston: Northwestern UP, 2012.

Bell, Betty Louise. Faces in the Moon. Norman: U of Oklahoma P, 1994.

---. "Literature by Indians." Encyclopedia of North American Indians, edited by Frederick E. Hoxie. Boston: Houghton, 1996, pp. 337-40.

---. "Burying Paper.” Here First: Autobiographical Essays by Native American Writers, edited by Arnold Krupat and Brian Swann. New York: Modern Library, 2000, pp. 3040.

Black, Michele C. et al. National Intimate Partner and Sexual Violence Survey 2010 Summary Report. Atlanta: Centers for Disease Control and Prevention, 2011.

Blaeser, Kimberly M. "Writing Voices Speaking: Native Authors and an Oral Aesthetic." Talking on the Page: Editing Aboriginal Oral Texts, edited by Laura J. Murray and Keren Rice. Toronto: U of Toronto P, 1999, pp. 53-68.

Bow, Leslie. Betrayal and Other Acts of Subversion: Feminism, Sexual Politics, Asian American Women's Literature. Princeton: Princeton UP, 2001. 
Cathy Caruth. "Trauma and Experience." Introduction. Trauma: Explorations in Memory, edited by Cathy Caruth. Baltimore: Johns Hopkins UP, 1995, pp. 3-12.

---. Unclaimed Experience: Trauma, Narrative, and History. Baltimore: Johns Hopkins U P, 1996.

Craps, Stef. "Beyond Eurocentrism: Trauma Theory in the Global Age." The Future of Trauma Theory: Contemporary Literary, and Cultural Criticism, edited by Gert Buelens, Sam Durrant, and Robert Eaglestone. London: Routledge, 2014, pp. 45-61.

Craps, Stef, and Gert Buelens. "Introduction: Postcolonial Trauma Novels," Studies in the Novel, vol. 40, no.1-2, 2008, pp. 1-12.

Deer, Sarah. The Beginning and End of Rape: Confronting Sexual Violence in Native America. Minneapolis: U of Minnesota P, 2015.

Dennis, Helen May. Native American Literature: Towards a Spatialized Reading. New York: Routledge, 2007.

Duran, Eduardo. Healing the Soul Wound: Counseling with American Indians and Other Native People. New York: Teachers College Press, 2006.

Felman, Shoshana and Dori Laub. Testimony: Crises of Witnessing in Literature, Psychoanalysis, and History. New York: Routledge, 1992.

Gibbs, Alan. Contemporary American Trauma Narratives. Edinburgh: Edinburgh UP, 2014. Hendrickson, Roberta Makashay. "Victims and Survivors: Native American Women Writers, Violence against Women, and Child Abuse." Studies in American Indian Literatures Series 2, vol. 8, no.1, 1996, pp. 13-24.

Justice, Daniel Heath. Our Fire Survives the Storm: A Cherokee Literary History. Minneapolis: U of Minnesota P, 2006. 
Krupat, Arnold. "Postcolonialism, Ideology, and Native American Literature.” Postcolonial Theory and the United States: Race, Ethnicity, and Literature, edited by Amritjit Singh and Peter Schmidt. Jackson: UP of Mississippi, 2000, pp. 73-94.

LaCapra, Dominick. Writing History, Writing Trauma. Baltimore: Johns Hopkins UP, 2001

Madsen, Deborah L. Beyond the Borders: American Literature and Post-Colonial Theory. London: Pluto Press, 2003.

---. “On Subjectivity and Survivance: Rereading Trauma through The Heirs of Columbus and The Crown of Columbus." Survivance: Narratives of Native Presence, edited by Gerald Vizenor. Lincoln: U of Nebraska P, 2008, pp. 61-87.

Miller, Nancy K., and Jason Tougaw, eds. Extremities: Trauma, Testimony, and Community. Champaign-Urbana: Illinois UP, 2002.

Million, Dian. "Felt Theory: An Indigenous Feminist Approach to Affect and History." Wicazo Sa Review, vol. 24, no. 2, 2009, pp. 53-76. doi:10.1353/wic.0.0043.

---. Therapeutic Nations: Healing in an Age of Indigenous Human Rights. Tucson: U of Arizona P, 2013.

Ortiz, Simon. "Towards a National Indian Literature: Cultural Authenticity in Nationalism." MELUS 8.2 (1981): 7-12. Rpt. American Indian Literary Nationalism, edited by Jace Weaver, Craig S. Womack and Robert Warrior. Albuquerque: U of New Mexico P, 2005, pp. 253-60.

Outka, Elizabeth. "Trauma and Temporal Hybridity in Arundhati Roy's The God of Small Things.” Contemporary Literature, vol. 52, no.1, 2011, pp. 21-53. doi:10.1353/cli.2011.0019. 
Poupart, Lisa M. "The Familiar Face of Genocide: Internalized Oppression among American Indians.” Hypatia, vol. 18, no. 2, 2003, pp. 86-100. doi:10.1111/j.15272001.2003.tb00803.x.

Radstone, Susannah. “Trauma Theory: Contexts, Politics, Ethics.” Paragraph, vol. 30, no.1, 2007, pp. 9-29. doi:10.3366/prg.2007.0015.

Roberts, Christina. 'Narrative Healing in Betty Louise Bell's Faces in the Moon: A Tribute to Cherokee Continuance." Studies in American Indian Literatures, vol. 25, no. 3, 2013, pp. 86-106. doi:10.5250/studamerindilite.25.3.0086.

Robertson, Kimberly. "Rerighting the Historical Record: Violence against Native Women and the South Dakota Coalition against Domestic Violence and Sexual Assault.” Wicazo Sa Review, vol. 27, no. 2, 2012, pp. 21-47. doi:10.5749/wicazosareview.27.2.0021.

Rodi-Risberg, Marinella, "Problems in Representing Trauma." Cambridge Critical Concepts: Trauma and Literature, edited by J. Roger Kurtz. NY: Cambridge UP, forthcoming. Romero, Channette. Activism and the American Novel: Religion and Resistance in Fiction by Women of Color. Charlottesville: U of Virginia P, 2012.

Singh, Amritjit and Peter Schmidt, eds. Postcolonial Theory and the United States: Race, Ethnicity, and Literature. Jackson: UP of Mississippi, 2000.

Smith, Andrea. Conquest: Sexual Violence and American Indian Genocide. Cambridge: South End P, 2005.

Tjaden, Patricia and Nancy Thoennes. Full Report of the Prevalence, Incidence, and Consequences of Violence against Women. Washington, DC: US Department of Justice, 2000.

Vickroy, Laurie. Reading Trauma Narratives: The Contemporary Novel and the Psychology of Oppression. Charlottesville: U of Virginia P, 2015. 
Visser, Irene. "Trauma Theory and Postcolonial Literary Studies.” Journal of Postcolonial Writing. vol. 47, no. 3, 2011, pp. 270-82. doi:10.1080/17449855.2011.569378. 